\title{
Should a pension reform be announced? A reply
}

\begin{abstract}
Fedotenkov (2016) shows that a reduction in the pay-as-you-go (PAYG) contribution rate leads to larger welfare losses for the first transitional generation if the reform is announced in advance. His analysis is based on expected lifetime utility at the reform announcement date. This note reconsiders the reform from the alternative perspective of implementation date. It argues that an announced reform may be preferable because it raises realized consumption of the first transitional generation in old age. Implications for social welfare evaluations are illustrated with a numerical example.
\end{abstract}

JEL Classification: E21, H55.

Keywords: Pension reform, announcement, savings, welfare.

\section{Introduction}

Many countries have recently reformed their public pension systems, or are soon planning to do so. One of the most popular reforms is a switch from pay-as-you-go (PAYG) to a more funded pension scheme. In a dynamically efficient economy, such a reform improves the welfare of the young and lowers the welfare of the current old (Breyer, 1989). To mitigate the losses of the old generation, governments may wish to announce the reform in advance so that agents may reallocate consumption in accordance with their intertemporal preferences.

In a recent paper, Fedotenkov (2016) challenges this intuition. He shows that an announced pension reform that reduces the PAYG contribution rate benefits all later generations but imposes larger losses on the first transitional generation. Hence, a government wishing to mitigate the losses of agents hurt most by the reform may prefer to implement the reform with no announcement.

The above result is based on expected lifetime utility at the reform announcement date. This note reconsiders the reform from the alternative perspective of implementation date. It is argued that an announced reform may be preferable because this raises realized old age consumption of the first transitional generation - an impact not captured in expected lifetime utility. This contrasts with expected old age consumption, which is lower under an announced reform and enters into expected utility (see Fedotenkov, p. 136).

The distinction between announcement date and implementation date has important implications for social welfare evaluations of announced and unannounced reforms; in particular, we show that unambiguous rankings of such reforms may not be possible even if generational weights are fully specified. Intuitively, this is because welfare impacts may differ ex ante and ex post, so that clear policy recommendations are no longer available. 


\section{Impact of the pension reform}

To make the above points, it suffices to focus on Equations (8),(9) and (10) of the model, reproduced here for convenience:

$$
\begin{gathered}
C_{t}^{y}=\left(1-\tau_{t}\right)(1-\alpha) k_{t}^{\alpha}\left(1-\frac{\alpha}{\tau_{t+1}^{e}(1-\alpha)(1+\rho)+\alpha(2+\rho)}\right) \\
C_{t+1}^{o}=\left(\frac{\alpha\left(1-\tau_{t}\right)(1-\alpha) k_{t}^{\alpha}}{\tau_{t+1}^{e}(1-\alpha)(1+\rho)+\alpha(2+\rho)}\right)^{\alpha}\left[\alpha+(1-\alpha) \tau_{t+1}^{e}\right] \\
k_{t+1}=\frac{\alpha\left(1-\tau_{t}\right)(1-\alpha) k_{t}^{\alpha}}{\tau_{t+1}^{e}(1-\alpha)(1+\rho)+\alpha(2+\rho)}
\end{gathered}
$$

where $\tau_{t}$ is the current PAYG contribution rate, and $\tau_{t+1}^{e}$ the expected future PAYG rate. ${ }^{1}$

Equation (1) is young age consumption. The term in big brackets is 1 minus the saving rate, and is increasing in $\tau_{t+1}^{e}$. Hence, young agents save more, and consume less, if a fall in pension benefits is anticipated. Equation (2) says that expected old age consumption depends on savings plus the expected share of output paid to pensioners, $(1-\alpha) \tau_{t+1}^{e}$. Equation (3) is capital accumulation: it links saving per young to labour income net of pension contributions, and is decreasing in the discount rate $\rho$ and the expected generosity of pensions $\tau_{t+1}^{e}$.

An announced pension reform reduces $\tau_{t+1}^{e}$. This lowers consumption when young and expected consumption when old. Hence, expected utility $U_{t}=\log \left(C_{t}^{y}\right)+\frac{1}{1+\rho} \log \left(C_{t+1}^{o}\right)$ falls, as shown by Fedotenkov (p. 136). Note that expected consumption $C_{t+1}^{o}$ is lower despite the fact that an announced reform raises capital accumulation; see Equation (3). This is because young agents expect to receive a smaller share of output at pension age, corresponding to a fall in $\left[\alpha+(1-\alpha) \tau_{t+1}^{e}\right]$ in Equation (2). Under an unannounced reform, by comparison, $C_{t+1}^{o}$ is unchanged since $\tau_{t+1}^{e}=\tau_{t}$.

When the reform is implemented in period $t+1$, old agents are hit with a fall in their share of output $\left[\alpha+(1-\alpha) \tau_{t+1}\right]$, regardless of whether the reform is announced or not. But the fall in consumption is smaller under the announced reform, because pensioners can consume out of their extra savings; see Equations (2) and (3). Hence, by sacrificing current consumption, the old enjoy more consumption at the date when the reform is implemented.

This is illustrated in Figure 1, which plots consumption under a pension reform which takes place at date 1 and is announced at date 0; the parameters match Fedotenkov (2016). ${ }^{2}$ The announced reform lowers consumption of the young at date 0 (upper panel), as indicated by Equation (1). But when these agents become old in period 1 they enjoy higher consumption than if the reform were not announced (lower panel). Notice that the latter effect refers to realized consumption at the reform implementation date, not expected old age consumption, which is lower under an announced reform. Hence, the date at which the pension reform is evaluated matters crucially for old age consumption.

\footnotetext{
${ }^{1}$ Population growth is set at zero as in the numerical example in Fedotenkov (2016). Full details of the model can be found in that paper.

${ }^{2}$ Consumptions of young and old are expressed relative to their pre-reform steady state values.
} 

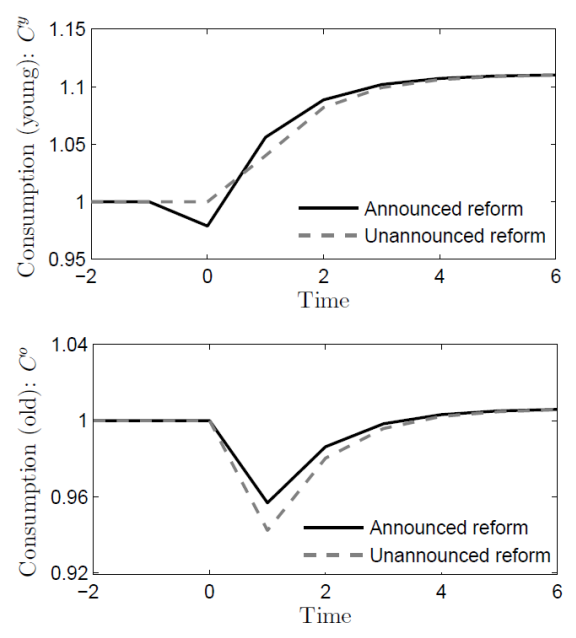

Figure 1: Consumption when young and old. Reform takes place at date 1.

\section{Social welfare}

The result that old age consumption is higher under an announced reform has implications for social welfare evaluations. To make this concrete, suppose we want to evaluate social welfare given by a discounted sum of lifetime utilities of current and future generations:

$$
W_{t}=\gamma^{-1} \bar{U}_{t-1}+\sum_{s=0}^{\infty} \gamma^{s} U_{t+s}
$$

where $0<\gamma<1$, and $\bar{U}_{t-1}=\log \left(C_{t-1}^{y}\right)+\frac{1}{1+\rho} \log \left(C_{t}^{o}\right)$ is utility of the initial old.

For the reform at hand, the government could evaluate welfare either from the perspective of $t=0$ (the announcement date) or $t=1$ (the implementation date). The welfare as of $t=0$ will differ in the announced and unannounced cases to the extent that expected lifetime utilities differ from $t=0$ onwards. This is because, as shown in Figure 1, consumption by the old is unchanged up to $t=0$ regardless of whether the reform is announced or not. ${ }^{3}$ Note that expected consumption of the old at the reform date gets counted in $t=0$ welfare, but their realized consumption does not. By comparison, welfare as of $t=1$ includes the consumption of the old at the reform date and their past consumption when young. Hence, the difference between the welfare functions at $t=0$ and $t=1$ is that the former includes expected consumption on the reform date, whereas the latter includes realized consumption.

Because realized consumption is higher under an announced reform, an unambiguous welfare ranking may not be possible even if the generational weights $\gamma^{s}$ are known. Welfare evaluations in the above example are reported in Table 1, where $E V_{0}$ is the equivalent variation based on date 0 welfare, and $E V_{1}$ is the equivalent variation based on date 1 welfare. A positive value indicates social welfare is higher under the unannounced reform. ${ }^{4}$

\footnotetext{
${ }^{3}$ Likewise, the young-age consumption of these agents at $t=-1$ is not affected by the reform.

${ }^{4}$ Equivalent variation is computed as the $\%$ increase in young-age consumption (from date $t$ on) that makes an announced reform welfare equivalent to an unannounced reform. Parameter values match Fig. 1.
} 
Table 1 - Welfare evaluations (\%)

\begin{tabular}{|ccc|}
\hline$\gamma$ & $E V_{0}$ & $E V_{1}$ \\
\hline 0.99 & 0.02 & -0.02 \\
0.95 & 0.11 & -0.10 \\
0.75 & 0.79 & -0.35 \\
0.50 & 2.03 & -0.17 \\
\hline
\end{tabular}

We see that welfare reversals occur for a range of values of the social discount factor, $\gamma$. These reversals are driven by the differing impact of the reforms on expected versus realized consumption in period 1 . In particular, the welfare evaluation at $t=1$ consistently ranks the announced reform better because it raises realized consumption of pensioners at date 1 , whereas the welfare evaluation at $t=0$ prefers the unannounced reform because it avoids a drop in expected future consumption at date 1.

\section{Conclusion}

Fedotenkov (2016) argues it may be preferable not to announce a shift from PAYG to a more funded pension scheme because this lowers expected utility of the first transitional generation at the reform announcement date. This note reconsidered the pension reform from the perspective of reform implementation date. We argued an announced reform may be preferable because, by raising capital accumulation, this gives the first transitional generation higher old age consumption. This result casts doubt on whether an unannounced reform is desirable. It also raises a difficulty inherent in social welfare evaluations of announced and unannounced reforms: there may be no clear ranking of such reforms. These results arise because both announcement date and implementation date are valid standpoints for welfare comparisons, yet the information revealed to agents differs in the two cases. Researchers are advised to keep this in mind when evaluating such reforms.

\section{Acknowledgements}

I would like to thank an anonymous referee and the Associate Editor, Eric Young, for helpful comments that improved the paper.

\section{References}

Breyer, F. 1989. On the intergenerational Pareto efficiency of pay-as-you-go financed pension systems. J. Inst. Theor. Econ. 145, 643-658.

Fedotenkov, I. 2016. Ignorance is bliss: Should a pension reform be announced? Econ. Lett. $147,135-137$. 